\title{
A New Dibenzofuran from the Barks of Sorbus commixta
}

\author{
Seong Yeon Choi ${ }^{\oplus 1}$, Birang Jeong ${ }^{\oplus 1}$, Hyeon Seok Jang ${ }^{\oplus 1}$, Jiho Lee ${ }^{\oplus 1}$ \\ Kiwon Ko $^{\oplus 1}$, Hyunha Kim ${ }^{\oplus 1}$, Jua Hong ${ }^{\oplus 1}$, Young Soo Bae ${ }^{\oplus 2}$ and \\ Heejung Yang ${ }^{\oplus * 1}$
}

\author{
${ }^{1}$ College of Pharmacy; Kangwon National University, Chuncheon 24341, Republic of Korea \\ ${ }^{2}$ College of Forest and Environmental Sciences, Kangwon National University, Chuncheon \\ 24341, Republic of Korea
}

(Received June 20, 2017; Revised September 13, 2017; Accepted Month September 14, 2017)

\begin{abstract}
A new dibenzofuran derivative, 1,2,4-trimethoxydibenzofuran-3,9-diol (7), was isolated from the ethyl acetate fraction of Sorbus commixta barks, along with six known compounds, lupeol (1), betulin (2), betulinic acid (3), ursolic acid (4), $\beta$-sitosterol (5) and $\beta$-pyrufuran (6). Their structures were determined by NMR spectroscopic analysis, including of ${ }^{1} \mathrm{H}$ and ${ }^{13} \mathrm{C}$ NMR, ${ }^{1} \mathrm{H}-{ }^{1} \mathrm{H}$ COSY, HSQC and HMBC spectra data. Cytotoxic activities of seven compounds were evaluated in five cancer cell lines, HEp-2, A549, MCF-7, PC-3 and SKOV-3 at the concentrations ranging from 10 to $100 \mu \mathrm{M}$.
\end{abstract}

Keywords: Sorbus commixta; triterpenes; dibenzofuran; 1,2,4-trimethoxydibenzofuran-3,9-diol; cytotoxicity. (C) 2018 ACG Publications. All rights reserved.

\section{Plant Source}

The barks of S. commixta was collected from Gamjeong-ri, Dong-Myeon, Chuncheon, Kangwon Province, Korea, in August 2015. It was identified by Prof. Young Soo Bae, College of Forest and Environmental Sciences, Kangwon National University, and has been stored in the Herbarium of College of Pharmacy, Kangwon National University (KNUP-SC-1).

\section{Previous Studies}

Sorbus commixta Hedl (Rosaceae) is mainly distributed in Korea and China. It has used for the treatment of neuralgia, cough and expectorant in folk remedies [1-3]. Until now, the study on the $S$. commixta has been mainly focused on the berries of $S$. commixta, and their biological activities, antiinflammatory and antioxidant effect, have been studied [4-6]. The anticancer activity of the bars of $S$. commixta has been previously reported, [7] but whether single compounds have the anti-proliferation activity against cancer cells have not reported yet. Previous research on the plant had reported the isolation of sorbic acid, chalcone glucoside, prunasin, amygdalin and triterpenoids such as lupenone 
and lupeol[4,8-9]. Recently, the methanol extract from the barks of $S$. commixta was shown to have antioxidant, anti-inflammatory and the potent radical scavenging activity $[4,5]$.

\section{Present Study}

In the present study, the ethyl acetate fraction of the barks of $S$. commixta showed the cytotoxic activity against the cancer cells. Further, we isolated seven compounds (1-7) from the barks of $S$. commixta and evaluated their cytotoxic activities against five cancer cell lines, HEp-2, A549, MCF-7, PC-3 and SKOV-3.

Extraction and isolation: The dried barks of S. commixta $(2.3 \mathrm{~kg})$ were extracted three times with $80 \%$ methanol for $3 \mathrm{~h}$. The extract was concentrated under reduced pressure to obtained total extract $(183.5 \mathrm{~g})$, which was then suspended in water and sequentially partitioned with $n$-hexane, EtOAc and $n$-butanol to give four fractions. The EtOAc fraction ( $46.6 \mathrm{~g})$ was subjected to silica gel C.C eluting with gradient of $n$-hexane/EtOAc and $\mathrm{CHCl}_{3} / \mathrm{MeOH}$ to afford ten fractions (Fr. 1 - 10). Among these, Fr. 4, 5 and 6 were used to obtain compounds 1-7.

Fr. 4 and 5 were subjected to normal phase silica gel C.C eluting with $n$-hexane/EtOAc (5:1 to 0:100) to give four and six sub-fraction, respectively (Fr. 4.1 - 4.4 and Fr 5.1 - 5.6). The sub-fraction Fr. 4.3 was re-crystallized with $\mathrm{MeOH}$ to yield compound 1 (5.8 mg). The sub-fraction Fr.5.6 was purified by $\mathrm{C}_{18} \mathrm{HPLC}\left(\mathrm{MeOH} / \mathrm{H}_{2} \mathrm{O}, 3: 2\right)$ to yield compound 5 (4.4 mg). Fr. 6 was subjected to reverse phase silica gel C.C eluting with $\mathrm{MeOH} / \mathrm{H}_{2} \mathrm{O}$ (9.5:0.5, isocratic) to give four sub-fractions (Fr. 6.1 6.4). The sub-fraction Fr. 6.1 was purified by $\mathrm{C}_{18} \mathrm{HPLC}\left(\mathrm{MeOH} / \mathrm{H}_{2} \mathrm{O}, 3.75: 1.25\right)$ to yield compound 6 $(3.1 \mathrm{mg})$ and compound $7(5.4 \mathrm{mg})$. Compound $3(4.0 \mathrm{mg})$ was isolated from the sub-fraction Fr. 6.2 by recrystallization in $\mathrm{MeOH}$. The residual solution of the sub-fraction Fr. 6.2 was purified by $\mathrm{C}_{18}$ $\mathrm{HPLC}\left(\mathrm{MeOH} / \mathrm{H}_{2} \mathrm{O}, 3: 2\right)$ to yield compound $2(1.9 \mathrm{mg})$. Compound $4(1.6 \mathrm{mg})$ was isolated the subfraction Fr. 6.4 by $\mathrm{C}_{18} \mathrm{HPLC}\left(\mathrm{MeOH} / \mathrm{H}_{2} \mathrm{O}, 3.5: 1.5\right)$.

Seven compounds were isolated from the EtOAc fraction using various chromatographic techniques. Compounds were identified as lupeol (1)[10], betulin (2)[11], betulinic acid (3)[11], ursolic acid (4) [12], $\beta$-sitosterol (5)[10], $\beta$-pyrufuran (6)[13] and 1,2,4-trimethoxydibenzofuran-3,9diol (7), respectively. The compound 7 isolated for the first time from nature. Their structures were determined by NMR spectroscopic analysis, including ${ }^{1} \mathrm{H}$ and ${ }^{13} \mathrm{C} N M R,{ }^{1} \mathrm{H}-{ }^{1} \mathrm{H}$ COSY, HSQC, and HMBC spectra data, which were acquired in the Central Laboratory of Kangwon National University (Figure 1).

1,2,4-trimethoxydibenzofuran-3,9-diol (7) : yellowish syrup; UV (MeOH): $\lambda \max (\log \varepsilon), 301$ (3.97), 280 (3.88), 285 (3.83); HRESIMS $m / z 289.0708$ [M-H] ${ }^{-}$(calcd. for $m / z 289.0712$ for $\mathrm{C}_{15} \mathrm{H}_{14} \mathrm{O}_{6}$ ); ${ }^{1} \mathrm{H}$ and ${ }^{13} \mathrm{C}$ NMR data see Table 1 and supporting information.

Cytotoxicity: HEp-2 cells were cultured in Dulbecco's modified Eagle's media (DMEM) and MCF-7, A549, PC-3 and SKOV3 cells were cultured in Roswell Park Memorial Institute medium (RPMI) supplemented with $10 \%$ fetal bovine serum (FBS), $100 \mathrm{IU} / \mathrm{mL}$ penicillin and $100 \mu \mathrm{g} / \mathrm{mL}$ streptomycin respectively. The cells were maintained at $37^{\circ} \mathrm{C}$ in a humidified atmosphere at air $(95 \%)$ and $\mathrm{CO}_{2}$ (5\%). Cell cytotoxicity was measured by MTT assay.

The ${ }^{1} \mathrm{H}$ NMR spectrum of 7 exhibited three methoxyl signals at $\delta 4.18\left(3 \mathrm{H}, s, \mathrm{OCH}_{3}-1\right), 4.16$ $\left(3 \mathrm{H}, s, \mathrm{OCH}_{3}-4\right)$ and $3.97\left(3 \mathrm{H}, s, \mathrm{OCH}_{3}-2\right)$, and two hydroxyl signals at $\delta 8.61(1 \mathrm{H}, s, \mathrm{OH}-9)$ and 5.91 $(1 \mathrm{H}, s, \mathrm{OH}-3)$. The ${ }^{13} \mathrm{C}$ NMR spectrum displayed twelve down-fielded carbons at around $\delta 109.4-$ 150.9 deduced the presence of two aromatic groups, and three up-fielded carbons at $\delta 62.4\left(\mathrm{OCH}_{3}-4\right)$, $61.4\left(\mathrm{OCH}_{3}-2\right)$ and $61.2\left(\mathrm{OCH}_{3}-1\right)$. The HSQC spectrum confirmed that three aromatic proton existed through the correlation between $\delta^{\mathrm{H}} 7.24(1 \mathrm{H}, d, J=8.1 \mathrm{~Hz}, \mathrm{H}-7)$ and $\delta^{\mathrm{C}} 127.8(\mathrm{C}-7), \delta^{\mathrm{H}} 7.00(1 \mathrm{H}, d, J$ $=8.1 \mathrm{~Hz}, \mathrm{H}-6)$ and $\delta^{\mathrm{C}} 109.3(\mathrm{C}-8)$, and $\delta^{\mathrm{H}} 6.79(1 \mathrm{H}, d, J=8.1 \mathrm{~Hz}, \mathrm{H}-8)$ and $\delta^{\mathrm{C}} 102.9(\mathrm{C}-6)$. (Table 1$)$. 

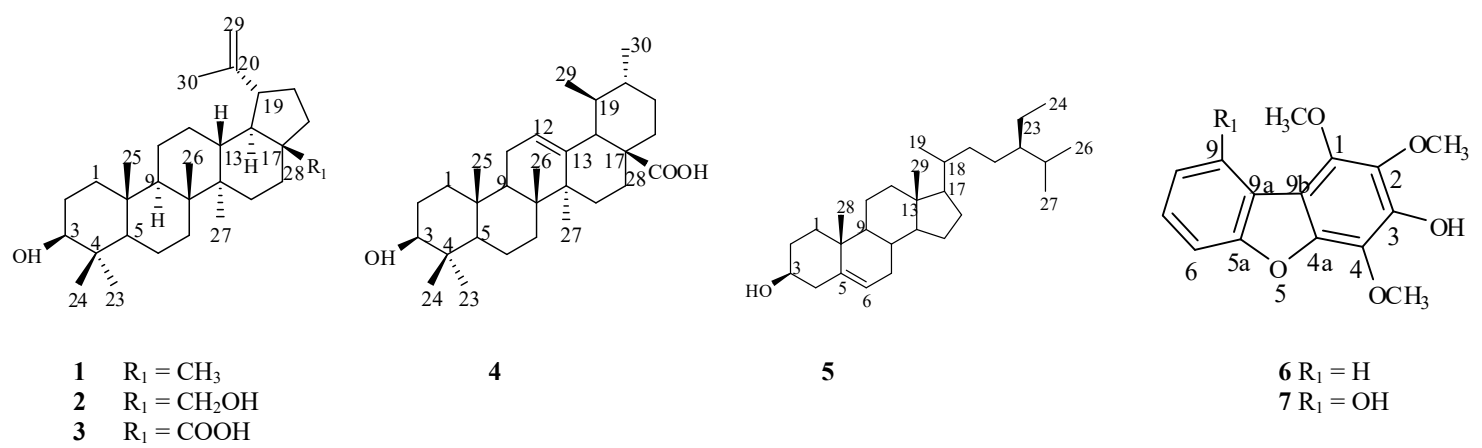

Figure 1. Structures of compounds 1-7 isolated from the barks of S. commixta

Table 1. ${ }^{1} \mathrm{H}$ NMR (400 MHz) and ${ }^{13} \mathrm{C}$ NMR (100 MHz) spectra data of compounds 6 and 7 in $\mathrm{CDCl}_{3}$ ( $\delta$ in ppm, $J$ in $\mathrm{Hz}$ ).

\begin{tabular}{ccccc} 
Compound & $\mathbf{6}$ & \multicolumn{1}{c}{$\mathbf{7}$} \\
\hline Position & $\delta_{\mathrm{H}}$ & $\delta_{\boldsymbol{C}}$ & $\delta_{\mathrm{H}}$ & $\delta_{\boldsymbol{C}}$ \\
\hline 1 & & 128.8 & & 129.4 \\
2 & & 136.6 & & 135.8 \\
3 & & 141.1 & & 141.3 \\
4 & & 142.7 & & 139.3 \\
$4 \mathrm{a}$ & & 143.0 & & 142.6 \\
$5 \mathrm{a}$ & & 155.9 & & 156.9 \\
6 & $7.50(1 \mathrm{H}, \mathrm{m})$ & 111.2 & $7.00(1 \mathrm{H}, d, J=8.2)$ & 102.9 \\
7 & $7.35(1 \mathrm{H}, \mathrm{m})$ & 125.7 & $7.24(1 \mathrm{H}, m)$ & 127.8 \\
8 & $7.29(1 \mathrm{H}, \mathrm{m})$ & 123.0 & $6.79(1 \mathrm{H}, d, J=8.1)$ & 109.3 \\
9 & & 121.9 & & 150.9 \\
$9 \mathrm{a}$ & & 123.5 & & 111.7 \\
$9 \mathrm{~b}$ & & 114.6 & & 109.4 \\
$\mathrm{OCH}_{3}-1$ & $4.05(3 \mathrm{H}, \mathrm{s})$ & 60.9 & $4.18(3 \mathrm{H}, s)$ & 61.2 \\
$\mathrm{OCH}_{3}-2$ & $4.18(3 \mathrm{H}, \mathrm{s})$ & 61.2 & $3.97(3 \mathrm{H}, s)$ & 61.4 \\
$\mathrm{OCH}_{3}-4$ & $3.99(3 \mathrm{H}, \mathrm{s})$ & 61.5 & $4.16(3 \mathrm{H}, s)$ & 62.4 \\
\hline
\end{tabular}

The ${ }^{1} \mathrm{H}$ and ${ }^{13} \mathrm{C}$ NMR spectroscopic data of compound 7 showed a quite similar pattern with $\mathbf{6}$, $\beta$-pyrufuran, except for the signal corresponding to a hydroxyl group. In the HMBC spectra, $\delta 8.61$ $(1 \mathrm{H}, s, \mathrm{OH}-9)$ showing the strong hydrogen signal of the hydroxyl moiety was strongly correlated with $\delta 111.7$ (C-9a), which described that the hydroxyl moiety was located at $\delta 150.9$ (C-9), not 102.9 (C-6) (Figure 2 and See Supporting file). Also, the correlation signals of $\delta 8.61(1 \mathrm{H}, s, \mathrm{OH}-9)$ with $\delta 150.9$ $(\mathrm{C}-9)$ and 109.3 (C-8) proved the presence of the hydroxyl moiety of $\delta 150.9$ (C-9).

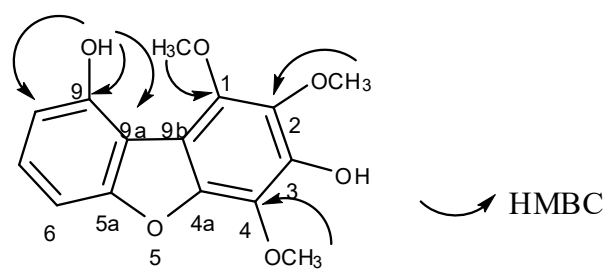

Figure 2. Chemical structure and HMBC correlations of compound 7 
Three concentrations $(1,50$ and $100 \mu \mathrm{M})$ of seven compounds and the positive control, docetaxel, were measured to confirm cytotoxicity in five cancer cell lines (HEp-2, MCF-7, A549, PC-3 and SKOV-3). Compounds 2, 3 and 4 showed significant cytotoxicity in HEp-2 and A549 at a concentration of $100 \mu \mathrm{M}$, compared to the positive control, docetaxel (Table 2). But, compounds $\mathbf{1}, \mathbf{5}$, 6 and 7 showed no or weak activities against five cancer cell (data not shown).

Table 2. The cytotoxic effects of compounds 2-4 against five cancer cell lines.

\begin{tabular}{cccccc}
\hline & HEp-2 & A549 & MCF-7 & PC-3 & SKOV-3 \\
\hline $\mathbf{2}$ & $43.5 \pm 2.32^{* * *}$ & $38.0 \pm 3.26^{* * *}$ & $-12.4 \pm 4.74$ & $19.2 \pm 7.68$ & $6.1 \pm 4.92$ \\
$\mathbf{3}$ & $37.2 \pm 3.08^{* * *}$ & $41.0 \pm 4.75^{* * *}$ & $23.3 \pm 22.76$ & $20.4 \pm 5.91$ & $15.8 \pm 16.86$ \\
$\mathbf{4}$ & $84.8 \pm 0.23^{* * *}$ & $80.8 \pm 0.31^{* * *}$ & $80.8 \pm 0.22^{* * *}$ & $76.6 \pm 3.89^{* * *}$ & $77.1 \pm 0.36^{* * *}$ \\
docetaxel & $83.6 \pm 1.69^{* * *}$ & $64.8 \pm 3.52^{* * *}$ & - & $88.4 \pm 3.73^{* * *}$ & $77.6 \pm 0.77^{* * *}$ \\
\hline $\begin{array}{l}\text { Analysis of cell cytotoxicity of } 100 \mu \text { M Compounds 2-4 using the MTT assay in cancer cell liens at 4 hours post-UV at } 590 \\
\text { nm irradiation. Columns, mean of three experiments; SD. }{ }^{*}, \mathrm{p}<0.05 ; * *, p<0.01 ; * * *, p<0.001 \text { for control (untreated) versus treated. }\end{array}$
\end{tabular}

\section{Acknowledgments}

This research was supported by Basic Science Research Program through the National Research Foundation of Korea (NRF) funded by the Ministry of Science, ICT \& Future Planning (No. NRF2015R1C1A1A01053892)

\section{Supporting Information}

Supporting Information accompanies this paper on http://www.acgpubs.org/RNP

\section{ORCID}

Seong Yeon Choi: $\underline{0000-0002-3425-6683}$

Birang Jeong: 0000-0002-1971-7779

Hyeon Seok Jang: 0000-0001-5538-0328

Jiho Lee: 0000-0003-0073-5763

Kiwon Ko: 0000-0001-7986-6357

Hyunha Kim: 0000-0001-7710-0657

Jua Hong: 0000-0002-6816-2482

Young Soo Bae: 0000-0003-1108-9269

Heejung Yang: 0000-0001-5986-9024

\section{References}

[1] L.R. Bhatt, M.S. Bae, B.M. Kim, G. Oh and K.Y. Chai (2009). A chalcone glycoside from the fruits of Sorbus commixta Hedl., Molecules 14, 5323-5327.

[2] J. Bae, G. Sim, J. Kim, H. Pyo, J. Yun and B. Lee (2007). Antioxidative activity of the hydrolytic enzyme treated Sorbus commixta Hedl. and its inhibitory effect on matrix metallopro-teinase-1 in UV irradiated human dermal fibroblasts, Arch.Pharm .Res. 30, 1116-1123.

[3] S.C. Hong, J.H. Yoo, M.H. Oh, H. Lee, Y.S. Park M.K. Pyo (2015). Effect of the mixture of Pueraria lobata and Sorbus commixta extract on the alcohol-induced hangover in rats, Nat. Prod. Sci. 21, 98-103.

[4] M. Kim, H. Seong and H. Sohn (2016). In-vitro antithrombosis activity of different parts of Sorbus commixta from Ulleung island, J. Life Sci. 26, 289-295..

[5] M.K. Na, S.M. Lee, Y.H. KIm and S.S. Kang (2002). Antioxidant compounds from the stem bark of Sorbus commixta, Nat. Prod. Sci. 8, 26-29. 
[6] D.G. Kang, E.J. Sohn, A.S. Lee, J.S. Kim, D.H. Lee and H.S. Lee (2007). Methanol extract of Sorbus commixta cortex prevents vascular inflammation in rats with a high fructose-induced metabolic syndrome, Am .J .Chin .Med . 35, 265-277.

[7] M. Lee, H. Lee, J. Lee, J. Oh, G. Choi and J. Kim (2002). Anticancer effect of Sorbus commixta Hedl extracts, Korean J. Med. Crop Sci. 10, 403-408.

[8] K. Takaishiand and H. Kuwajima (1976). Prunasin and amygdalin from Sorbus commixta, Phytochemistry 15, 1984.

[9] S. Lee and C. Lee (1999). Isolation and gas chromatographic analysis of lupenone and lupeol from Sorbus cortex, Anal. Sci. Technol. 12, 136-140.

[10] S. Mouffok, H. Haba, C. Lavaud, C. Long and M. Benkhaled (2012). Chemical constituents of Centaurea omphalotricha Coss. \& Durieu ex Batt. \& Trab. Rec. Nat. Prod. 6, 292-295.

[11] G. Uddin, B. Siddiqui, M. Alam, A. Sadat, A. Ahmad and A. Uddin (2011). Chemical constituents and phytotoxicity of solvent extracted fractions of stem bark of Grewia optiva Drummond ex burret, Middle-East. J Sci Res. 8, 85-91.

[12] R. A. El-shiekh, D.A. Al-Mahdy, M. S. Hifnawy, T. Tzanova, E. Evain-Bana, S. Philippot, D. Bagrel, E. A. Abdelsattar (2017). Chemical and biological investigation of Ochrosia elliptica Labill. cultivated in Egypt, Rec. Nat. Prod. 11, 552-557.

[13] M.S. Kemp, R.S. Burden and R.T. Loeffler (1983). Isolation, structure determination, and total synthesis of the dibenzofurans $\alpha$-and $\beta$-pyrufuran, new phytoalexins from the wood of Pyrus communis L. J. Chem. Soc. Perkin Trans.1.0, 2267-2272.

$$
\text { A } \underset{\substack{\text { publications } \\ \text { (C) 2018 ACG Publications }}}{\text { G }}
$$

